\title{
STUDI BUDAYA NONMATERIAL WARGA JATON
}

\author{
Suzy Azeharie, Sinta Paramita, Wulan Purnama Sari \\ Fakultas Ilmu Komunikasi Universitas Tarumanagara Jakarta, \\ Jl. S.Parman No.1 Jakarta 11440 \\ Telp. (021) 56960586 / Email: suzya@fikom.untar.ac.id
}

\begin{abstract}
Jaton village is situated in the heart of where the majority of the population is Christian. For hundreds of years the residents of Jaton Village lived side by side in harmony with the majority of Minahasa tribes who had different religions. A long historical factor makes Jaton Village unique because residents of Jaton Village are direct descendants of Kyai Modjo, a religious teacher from Prince Diponogoro, who was banished by Dutch colonialists along with 63 of his followers to the Tondano area in 1828. Amid the increasing number of violence committed by one religious group in another religion, this research is aim to see a form of nonmaterial culture in Jaton society. This research will answer the question of what form of non-material cultures includes values, norms and regulations for the people of Jaton Village, and how are the values, norms and beliefs passed on to the next generation. The method used is qualitative with case study approach through observation and in-depth interview. The results showed that the Jaton community still holds an ancestral culture originating from Java. In addition, the norms created are mixed up, so there is no norm that limits behavior or action. However, the most obvious thing to hold firmly is the norm of Islamic teachings which is their belief.
\end{abstract}

Keywords: culture, jaton village, nonmaterial culture, norms, values

\begin{abstract}
Abstrak
Desa Jaton terletak di jantung dimana mayoritas penduduknya beragama Kristen. Selama ratusan tahun, penduduk Desa Jaton hidup berdampingan dengan mayoritas suku Minahasa yang memiliki agama yang berbeda. Faktor historis yang panjang menjadikan Desa Jaton unik. Hal ini dikarenakan penduduk Desa Jaton adalah keturunan langsung Kyai Modjo, yang merupakan guru agama dari Pangeran Diponogoro, yang dibuang oleh penjajah Belanda bersama dengan 63 pengikutnya ke daerah Tondano pada tahun 1828. Di tengah peningkatan jumlah kekerasan yang dilakukan oleh satu kelompok agama terhadap agama lain, penelitian ini bertujuan untuk melihat bentuk budaya nonmaterial dalam masyarakat Jaton. Penelitian ini akan menjawab pertanyaan tentang apa bentuk budaya non-material yang mencakup nilai, norma dan peraturan bagi masyarakat Desa Jaton, dan bagaimana nilai, norma dan keyakinan diteruskan ke generasi berikutnya. Metode yang digunakan adalah kualitatif dengan pendekatan studi kasus melalui observasi dan wawancara mendalam. Hasil penelitian menunjukkan bahwa komunitas Jaton masih memegang budaya leluhur yang berasal dari Jawa. Selain itu, norma yang dibuat bercampur aduk, sehingga tidak ada norma yang membatasi perilaku atau tindakan. Namun, hal yang paling jelas untuk dipegang teguh adalah norma ajaran Islam yang merupakan keyakinan mereka.
\end{abstract}

Kata Kunci : budaya, budaya nonmaterial, desa jaton, nilai, norma

\section{Pendahuluan}

Indonesia terkenal sebagai negara multikultur yang memiliki banyak budaya, karena terdiri dari beragam etnis dan ras, kepercayaan dan budaya. Konsep multikultural merupakan perilaku terbuka yang ditandai adanya penerimaan atas perbedaan (Dasrun, Kuswarno, Zubair, \&
Hafiar, 2017). Keragaman budaya negeri ini dapat dilihat dari macam bentuk, seperti nilai, norma, alat musik, tarian, bahasa, adat pernikahan, adat kematian, adat kelahiran, upacara, ritual dan sebagainya. Keanekaragaman budaya inilah yang menjadikan Indonesia mempunyai keunggulan dalam hal kepemilikan potret 
kebudayaan yang lengkap dan bervariasi (Rahmansyah, 2016)

Di sisi lain keberagaman ini juga dapat berpotensi memicu berbagai kekerasan dengan sebab dan akibat yang berbeda. Berbagai konflik kekerasan atas nama agama menjadi sesuatu yang kerap ditemui di negeri ini. Lay (2009) mengatakan ada beberapa variasi kekerasan antara lain kekerasan yang melibatkan organisasi massa dalam komunitas agama yang sama. Lalu ada kekerasan yang melibatkan agama yang berbeda. Sejak Republik Indonesia berdiri sampai November 2001, menurut Lay, terdapat 858 gereja yang dirusak. Kuil Hindu dirusak di Legian, Kuta, Tuban pada tahun 2005. Lalu konflik antar agama Islam dengan Kristen di Ambon pada tahun 1999.

Sejak Kampung Jaton berdiri di akhir tahun 1828, sampai hari ini tidak pernah terjadi eskalasi konflik kekerasan agama antara umat Kristen dan Muslim di daerah Tondano. Pada dua kelompok masyarakat yang berbeda keyakinan tersebut memiliki seperangkat peraturan dan norma yang dimiliki bersama oleh para anggota masyarakat. Apabila peraturan dan norma tersebut dilaksanakan oleh anggota masyarakat maka menurut William Haviland akan melahirkan perilaku yang dipandang layak dan dapat diterima oleh suatu masyarakat (inrevolzon, 2013).

Budaya pada sebuah masyarakat bertujuan untuk mempermudah hidup manusia dengan cara mengajarkan cara untuk beradaptasi dalam masyarakat. Samovar, Porter, \& McDaniel (2010) menjelaskan bahwa karakteristik utama dari budaya adalah dipelajari dan dibagikan melalui dongeng, mitos dan legenda. Budaya juga diturunkan dari generasi ke generasi untuk mempertahankan nilai-nilai yang terkandung dalam suatu budaya dan memastikan di masa depan budaya tersebut tetap ada.

Menurut Alo Liliweri, kebudayaan dapat dibedakan berdasarkan wujudnya, yaitu budaya material dan budaya nonmaterial. Budaya material adalah semua objek material yang dibuat, dihasilkan, dan dipakai oleh manusia, mulai dari bendabenda sederhana seperti alat rumah tangga, pakaian, dan makanan hingga desain arsitektur, teknologi komputer dan kapal terbang. Budaya material merupakan segala sesuatu yang diciptakan oleh manusia dan dapat ditangkap oleh panca indra. Sedangkan budaya nonmaterial digunakan sebagai rujukan kelompok masyarakat, karena budaya nonmaterial hanya ada dalam bentuk gagasan atau ide yang diikuti dengan penuh kesadaran dalam bentuk nilai, norma dan kepercayaan (Liliweri, 2009).

Budaya nonmaterial yang tidak memiliki wujud secara fisik ini memiliki peranan yang lebih besar daripada budaya material dalam masyarakat. Alo Liliweri menegaskan bahwa budaya nonmaterial dijadikan pedoman atau rujukan dalam kelompok masyarakat. Berarti nilai, norma, dan kepercayaan dalam suatu masyarakat merupakan unsur terpenting dalam suatu budaya, karena anggota masyarakat harus mengikuti dan tunduk pada budaya nonmaterial tersebut agar dapat diterima dalam masyarakat. Samovar, Porter, \& McDaniel (2010) 
mengenalkan kata "enkulturasi" atau proses pembelajaran suatu budaya secara total yang merupakan cara mempelajari kebudayaan melalui penggunaan simbol, bahasa verbal maupun nonverbal.

Hal senada dikatakan pula oleh William Haviland yang mengatakan bahwa kebudayaan adalah hasil belajar dan bukan warisan biologis. Kebudayaan merupakan "warisan sosial" umat manusia. Proses penerusan kebudayaan dari generasi satu kepada generasi berikutnya disebut sebagai enkulturasi (Haviland, Prins, McBride, \& Walrath, 2010).

Selain budaya nonmaterial, unsur penting dalam budaya adalah sejarah. Menurut Samovar, Porter, \& McDaniel (2010) semua budaya percaya bahwa sejarah merupakan sebuah diagram yang memberikan petunjuk bagaimana hidup pada masa kini. Berdasarkan hal tersebut dapat disimpulkan bahwa sejarah memiliki peranan dalam mempertahankan suatu budaya. Pada praktiknya dalam kehidupan bermasyarakat, seringkali dua budaya yang berbeda saling berinteraksi dalam kehidupan bermasyarakat. Kelompok masyarakat yang memiliki budaya berbeda saling berinteraksi dalam satu lingkungan tempat tinggal yang sama seperti yang terjadi di Kampung Jaton.

Kampung Jaton merupakan sebuah kampung yang berada di daerah Tondano, Minahasa, Sulawesi Utara. Jaton adalah kampung Islam yang berada di daerah dengan mayoritas masyarakat beragama Kristen. Selama ratusan tahun warga Kampung Jaton hidup berdampingan dan rukun dengan warga mayoritas suku Minahasa yang berbeda agama.
Penelitian yang telah dilakukan di Kampung Jaton sudah cukup banyak. Salah satunya dilakukan oleh Tim Babcock yang meneliti tentang Muslim di tanah Minahasa dengan akar yang berasal dari Jawa. Penelitian Babcock (1981) meneliti mengenai kebijakan pemerintah kolonial Belanda untuk "membuang" orang-orang yang mengangkat senjata pada Belanda, menjadikan kedatangan rombongan dari Pulau Jawa ini sebagai awal dari eksistensi agama Islam di bumi Minahasa.

Penelitian ini berbeda dengan penelitian Babcock terdahulu karena tidak menitikberatkan pada eksistensi agama Islam di Kampung Jaton, melainkan pada bentuk dari budaya nonmaterial di Kampung Jaton. Dalam penelitian ini akan mengungkap bagaimanakah bentuk-bentuk budaya nonmaterial yang meliputi nilai, norma dan peraturan pada masyarakat Kampung Jaton di Tondano yang merupakan kelompok masyarakat minoritas di Minahasa. Kemudian tujuan dari penelitian ini adalah untuk mengetahui bagaimana nilai, norma dan kepercayaan itu diturunkan pada generasi berikutnya.

Teori-teori yang digunakan dalam penelitian ini adalah teori Kebudayaan. Sebab antara komunikasi dan kebudayaan merupakan satu kesatuan integral yang tidak dapat berdiri sendiri. Edward T. Hall dalam Larry A. Samovar, et.al menegaskan hal ini dengan mengatakan bahwa kebudayaan adalah komunikasi dan komunikasi adalah kebudayaan. Sebab kebudayaan terbentuk karena adanya masyarakat. Sebaliknya masyarakat terbentuk karena adanya kebudayaan (Samovar et al., 2010). 
Iris Varner dan Linda Beamer dalam Liliweri (2009) menyebutkan bahwa kebudayaan adalah perilaku yang telah tertanam dan merupakan totalitas dari sesuatu yang dipelajari manusia. Akumulasi dari pengalaman yang dialihkan melalui sosialisasi dalam bentuk pembelajaran sosial atau social learning. Kebudayaan juga merupakan pandangan hidup dari sekelompok orang dalam bentuk perilaku, kepercayaan, nilai dan simbol-simbol yang diwariskan melalui proses komunikasi dan peniruan dari satu generasi kepada generasi berikutnya.

Proses komunikasi yang berlangsung [antarpribadi yang benar] berbeda budaya termasuk perbedaan generasi tersebut menurut William G. Scoot dalam Suryani (2013) dipengaruhi oleh beberapa faktor, yaitu the act [perbuatan], the scene [adegan], the agency [perantara], the purpose [tujuan]. Perbuatan komunikasi mengharuskan pemakaian lambang yang bisa dimengerti secara baik dan hubungan yang dilakukan oleh manusia. Umumnya lambang tersebut dinyatakan dengan bahasa atau dalam tandatanda lain. Kemudian adegan sebagai salah satu faktor dalam komunikasi menekankan apa yang dilakukan, simbol apa yang digunakan dan arti dari yang dikatakan. Selanjutnya the agent atau pelaku, individu yang mengambil bagian dalam hubungan komunikasi dinamakan pelaku komunikasi. Pengirim dan penerima yang terlibat dalam hubungan komunikasi adalah contoh dari pelaku komunikasi tersebut. Selanjutnya the agency atau perantara yaitu alat yang dapat membangun terwujudnya perantara. Alat itu dapat berwujud komunikasi lisan, tatap muka, alat komunikasi tertulis seperti surat perintah, memo, buletin, nota, surat tugas dan lainnya yang sejenis. Terakhir adalah the purpose atau tujuan.

Ditambahkan juga bahwa kebudayaan merupakan komunikasi simbolis berupa ketrampilan kelompok, pengetahuan, sikap, nilai dan motif. Makna dari simbol simbol yang disebutkan tadi dipelajari dan lalu disebar luaskan dalam masyarakat melalui institusi. Hal yang sama terjadi pada masyarakat Kampung Jaton yang meneruskan norma dan nilai serta kepercayaan yang didapat dari satu generasi ke generasi berikutnya. Meskipun menurut Lay (2009) terdapat permasalahan, antara lain apakah masyarakat di daerah tersebut cepat atau lambat menerima pembaruan selain apakah unsur budaya asli mudah atau sukar untuk diterima (Lay, 2009).

Proses penerusan kebudayaan dari generasi satu kepada generasi berikutnya disebut Haviland sebagai enkulturasi (Haviland et al., 2010). Sebab kebudayaan diperoleh sebagai hasil belajar dan bukan warisan biologis. Ralph Linton dalam Haviland mengatakan kebudayaan merupakan "warisan sosial" umat manusia. Nilai, menurut Alo Liliweri, merupakan sebuah konsep penting dalam kebudayaan karena nilai membimbing manusia untuk menentukan apakah sesuatu itu boleh atau tidak boleh dilakukan (Liliweri, 2009). Nilai, menurutnya meliputi penilaian tentang baik buruknya obyek, peristiwa, tindakan sementara norma merupakan standar perilaku. Jadi norma merupakan 
nilai budaya yang merupakan standar dasar dari kehidupan sebuah kelompok.

\section{Metode Penelitian}

Penelitian ini menggunakan pendekatan kualitatif. Pendekatan kualitatif menurut Suyanto \& Sutinah (2013) sesuai bila penelitian itu ingin mendeskripsikan latar dan interaksi yang kompleks dari partisipan serta memahami keadaan yang terbatas jumlahnya dengan fokus yang mendalam dan rinci.

Pendekatan kualitatif ini dipilih peneliti karena hendak mengungkapkan bagaimana budaya nonmaterial pada masyarakat Jaton di Tondano. Metode penelitian yang digunakan adalah kualitatif. Menurut Bogdan dan Taylor dalam Moleong metode kualitatif merupakan prosedur penelitian yang menghasilkan data deskriptif berupa kata-kata tertulis atau lisan dari orang-orang dan perilaku yang dapat diamati dengan mengarahkan latar dan individu secara holistik (Lexy J. Moleong, 2017).

Pendekatan yang digunakan adalah pendekatan kualitatif studi kasus. Studi kasus dipilih karena fenomena di Kampung Jaton merupakan kasus yang cukup unik. Menurut (Yin, 2014) studi kasus adalah sebuah metode penelitian ketika pertanyaan how (bagaimana) dan why (mengapa) diajukan dalam sebuah penelitian. Metode ini cocok untuk menganalisis lebih jauh sebuah fenomena secara mendetail seperti nilai budaya nonmaterial masyarakat Kampung Jaton.

Objek penelitian ini dalam penelitian ini adalah masyarakat di Kampung Jaton, Minahasa, Sulawesi Utara. Secara spesifik data yang dalam penelitian ini diperoleh dari key informant Mody Maukar (67), seorang pensiunan Perusahaan Ekspedisi berasal dari Minahasa keturunan keluarga Maukar. Kemudian Kedua, Aisha (62), istri dari Mody Maukar, yang merupakan keturunan kesembilan dari Kyai Pajang, salah seorang pengikut Kyai Modjo. Informan lain dalam penelitian ini adalah Asrul (48) seorang pemuka masyarakat keturunan Kyai Pajang, Rani (23) putri pasangan Maukar dan Aisha dan Rev. Dr. Nico Gara (70) mantan Sekretaris Jenderal Gereja Masehi Injil Minahasa, seorang tokoh masyarakat terkemuka Minahasa. Data diperoleh melalui wawancara mendalam dengan narasumber dan observasi kemudian ditambah dengan studi pustaka yang dilakukan oleh peneliti.

\section{Hasil Penelitian dan Pembahasan}

Kampung Jawa Tondano, terletak di Kecamatan Tondano Utara, Kabupaten Minahasa, Provinsi Sulawesi Utara. Warga Kampung Jaton merupakan keturunan dari salah seorang pahlawan Perang Jawa karismatik bernama KH Muhammad Khalifah Modjo atau dikenal sebagai Kyai Modjo. Kyai Modjo merupakan guru agama Islam Pangeran Diponegoro yang berperang melawan kolonialisme Belanda tahun 1825-1828.

Bersama putranya, Gazali, yang berumur 5 tahun dan 63 pengikutnya Kyai Modjo ditangkap oleh Belanda tahun 1828 dan dibuang ke Minahasa. Dalam masa pembuangannya Kyai Modjo melanjutkan usahanya menyebarluaskan agama Islam di Minahasa (Martinus, 2016).

Dalam pengasingan tersebut, menurut Finneke Wolajan, selain Kyai Modjo, 
terdapat pula beberapa ulama agama Islam antara lain Kyai Teuku Madja, Tumenggung Pajang, Pati Urawan, Kyai Baduran, dan Kyai Hasan Bedari serta pengikut lainnya yang semuanya laki-laki (Wolojan, 2015). Keenam puluh tiga orang pengikut Kyai Modjo ini kemudian menikah dengan perempuan asli dari Minahasa dan beranak pinak di Kampung Jaton. Aisha, istri key informant Mody Maukar, merupakan keturunan ke-9 dari Kyai Pajang yang merupakan salah satu pengikut Kyai Modjo.

Berikut akan dijabarkan mengenai hasil wawancara dengan narasumber. Mody Maukar narasumber utama merupakan putra daerah Minahasa yang berpindah agama dari Kristen menjadi Islam ketika ia menikahi Aisha. Dari pernikahan mereka lahir Hendi dan Rani. Saat ini Mody Maukar dan keluarganya tinggal di sebuah rumah yang cukup besar di tepi jalan raya Kampung Jaton.

\section{Budaya Nonmaterial: Nilai, Baik Buruknya Peristiwa atau Tindakan}

Menurut key informant, Mody Maukar, fenomena seseorang berpindah agama tidak dipandang sebagai sesuatu yang luar biasa di kalangan keluarga. Fenomena ini kemungkinan dipengaruhi oleh sejarah yaitu salah seorang keturunan langsung Kyai Modjo bernama Husein yang menikahi seorang gadis dari Papakelan Minahasa dan berpindah menjadi Kristen.

Nenek dari key informant, Aisha, yang berasal dari Wayong Tomohon beragama Kristen dan ketika ia menikah pindah agama dan menjadi Muslim. Sampai sekarang keluarga Wayong, baik yang Kristen maupun yang Muslim, tetap harmonis dan hidup rukun. Apabila keluarga Kristen merayakan Natal maka keluarga Islam berkunjung. Sebaliknya ketika Lebaran maka keluarga Wayong yang Kristen pun mengunjungi rumah keluarga yang merayakan Lebaran.

Di keluarga Maukar hal yang hampir sama terjadi. Orang tua Mody Maukar memiliki sembilan anak. Mereka yang terdiri dari lima perempuan dan empat laki-laki. Semua anak laki-laki menikahi dengan perempuan Islam dan berpindah agama menjadi Islam sementara kelima anak perempuannya tetap beragama Kristen. Meskipun demikian hubungan kekeluargaan diantara kesembilan bersaudara tetap baik. Hubungan kekerabatan diantara kedua kelompok yang berlainan kepercayaan ini tampaknya membuat setiap orang belajar bersikap toleran dan saling menghormati akibat munculnya kesadaran yang dikatakan Mody Maukar, "bahwa leluhur opa warga Jaton berasal dari Jaton dan leluhur oma dari Minahasa".

Meskipun nenek moyang warga Jaton yang berasal dari Jawa, sudah menetap selama lebih dari 150 tahun di tanah Minahasa, namun ada nilai-nilai budaya Jawa yang tetap diteruskan kepada generasi muda. Menurut Mody Maukar yang diteruskan adalah budaya bersalawat atau "asrokalan" setiap malam Jumat. Saat "asrokalan", anak-anak Jaton membaca Kitab Barzanji dengan irama Melayu. Kitab Barzanji adalah kitab perjalanan hidup Nabi Muhammad SAW. Selain pada saat “asrokalan", Kitab Barzanji juga dibacakan warga Jaton pada saat perayaan Maulid Nabi Muhammad SAW. Maulid adalah perayaan 
hari kelahiran Nabi Muhammad SAW. Pada saat Maulid ini Kitab Barzanji dibacakan dalam nada seperti menyanyikan kidung Jawa. Ritual ini oleh warga Jaton dikenal sebagai acara "Sholawat Jowo" (wawancara dengan Mody Maukar, tanggal 4 April 2017 di Tondano).

Selesai Sholawat Jowo, diadakan santap bersama dengan "ambeng" yaitu nasi dengan ayam yang disebut "engkung”. Ayam engkung ini bisa dibakar atau dibuat gudeg. Di Kampung Jaton, gudeg merupakan makanan asli Jawa yang lazim dibuat apabila warga memperingati kematian seseorang di hari ketujuh dan hari ke 40. Gudeg juga dibuat untuk merayakan akikah atau perayaan tujuh bulanan kehamilan. Rasa gudeg di Kampung Jaton sudah mengalami modifikasi selera. Kalau gudeg di Jawa lebih manis maka gudeg Minahasa rasanya lebih gurih.

Nilai lain yang diteruskan pada generasi muda Jaton adalah mengunjungi tetangga Nasrani yang sedang memperingati 40 hari kematian salah seorang anggota keluarga. Pada saat itu warga Jaton membawa makanan ke rumah keluarga yang wafat dan lalu kemudian makanan itu disantap bersama secara buffet. Tradisi ini dinamakan "mekan". Khusus untuk warga Jaton disediakan satu meja makan yang dinamakan meja makan "nasional" yang berarti semua makanan terhidang halal disantap bagi warga Jaton. Bila warga Jaton yang wafat tradisi "mekan" ini tidak dilakukan karena umat muslim umumnya tidak melakukan makan-makan ketika sedang berduka cita (wawancara dengan Rani Maukar, tanggal 4 April 2017 di Jaton, Tondano).
Tradisi "mekan" diperkirakan berakar dari sejarah bahwa leluhur warga Jaton berasal dari Yogyakarta dan merupakan pendatang di tanah Minahasa. Sebagai kelompok yang datang terakhir, warga asal Jawa harus bersikap rendah hati dan wajib melakukan pendekatan sosial pada warga lokal. Kerendahan hati serta sikap orang Jawa yang luwes menurut Aris Prasetyo menjadi salah satu unsur mereka diterima dengan baik oleh kelompok Minahasa. (Prasetyo, 2011)

Hal yang sedikit berbeda terjadi pada kelompok etnis Jawa dan Bugis di Samarinda. Meskipun kedua kelompok etnis tersebut sama-sama menetap di Samarinda akan tetapi menurut Muhammad Risky Jaya Utama, keduanya hanya sedikit tampak berkelompok. (Utama, 2017)

Perspektif lain didapat dari Rev. Dr. Nico Gara, salah seorang pengajar senior pada Sekolah Tinggi Agama Kristen di Manado yang mengungkapkan bahwa tahun 1885 Sidney Hickson seorang warga Inggris menulis "A Naturalist in North Celebes" yang mengungkapkan bahwa pelabuhan Manado kala itu dipenuhi dengan pedagang dari Malaka, Arab, Tiongkok dan Eropa yang ingin mendapatkan kopra (wawancara dengan Nico Gara, tanggal 5 April 2017 di Manado). Hal tersebut berarti sejak lama warga Minahasa telah terbiasa berinteraksi dengan warga lain yang berbeda ras maupun kepercayaan sehingga kehadiran warga Jaton di saat awal masa pengasingan mereka di Tondano pada akhir tahun 1828 diterima dengan relatif baik. Apalagi warga Jaton memiliki keahlian bercocok tanam yang kemudian diajarkan di Tondano. 
Nilai lain yang diteruskan adalah "pungguan" yaitu acara bersih kubur atau ziarah. Pungguan dilakukan sekitar satu minggu sebelum tibanya bulan Ramadhan, khususnya di kompleks pemakaman Kyai Modjo. Saat ritual pungguan seluruh keturunan Jaton yang ada di daerah Sulawesi Utara, baik tua maupun muda akan datang berkunjung dengan menenteng pacul, sapu dan ember berisi kembang. Acara pungguan dimulai dengan membersihkan kompleks makam, lalu dilakukan tabur bunga dan doa kubur yang ditutup dengan makan bersama di sekitar kompleks pemakaman. (Alwie, 2008)

Tradisi pungguan tidak lazim ditemukan di kalangan masyarakat Jawa, melakukan makan makan bersama seluruh keluarga di area pemakaman. Hal ini sejalan dengan pendapat Horton dan Chester dalam (Nugroho, Lestari, \& Wiendijarti, 2012) yang menegaskan bahwa tidak ada kebudayaan yang sama sekali statis. Setiap kebudayaan harus berubah untuk mempertahankan kelangsungannnya. Jadi dalam situasi seperti ini, etnosentrisme meningkatkan kestabilan kebudayaan dan kelangsungan hidup kelompok sedangkan dalam situasi lain etnosentrisme meruntuhkan kebudayaan dan memusnahkan kelompok.

Sementara itu norma adalah aturan yang mengatur tentang hukuman atau ganjaran dalam bentuk sesuai dengan variasi posisi sosial orang dalam relasi antar manusia. Semua tindakan manusia memiliki objek akibat tertentu dan norma secara khusus memberikan akibat sosial bagi seseorang saat dia menampilkan tindakan itu (Liliweri, 2009).
Kampung Jaton merupakan sebuah kawasan dengan masyarakat beragama Islam. Norma yang diteruskan secara turun-temurun mengalir seiring dengan perkembangan zaman. Kebiasaan, praktik dan tradisi terus hidup dan berkembang serta diwariskan pada generasi berikutnya.

Menurut salah satu key informant, Asrul, norma yang berlaku di Jaton sudah tidak terlalu rigid lagi. Hal tersebut disebabkan karena warga Jaton sudah membaur dengan masyarakat Minahasa. Ketika seseorang akan menyelenggarakan pesta, maka pesta di Kampung Jaton baru diadakan selepas waktu Maghrib. Hal tersebut disebabkan waktu shalat Maghrib yang sangat singkat. Sementara untuk siang hari, acara perkawinan, baru diadakan setelah waktu Dzuhur dan akan berakhir sebelum shalat Ashar tiba. Tidak mengherankan bila seluruh kegiatan di Kampung Jaton harus berhenti saat adzan bergema di masjid. Hal tersebut sesuai dengan pendapat William Scoot dalam Wahidah bahwa perbuatan komunikasi mengharuskan pemakaian lambang yang dapat dimengerti secara baik dan hubungan yang dilakukan oleh manusia. Umumnya lambang tersebut dinyatakan dengan bahasa atau dalam tandatanda lain. Dalam hal ini suara azan sebagai panggilan shalat dimengerti secara baik oleh masyarakat Kristiani dan juga masyarakat Muslim.

\section{Simpulan}

Berdasarkan hasil penelitian dan pembahasan di atas maka dapat disimpulkan beberapa poin utama yang menjadi hasil penemuan dalam penelitian ini. Pertama, meskipun masyarakat Jaton telah bermukim 
di bumi Minahasa lebih dari 150 tahun yang lalu, akan tetapi nilai-nilai dan norma yang merupakan bentuk budaya nonmaterial teguh dipegang kuat oleh masyarakat Jaton. Nilai dan norma tersebut hampir seluruhnya merupakan nilai dan norma agama Islam seperti tradisi "asrokalan" atau sholawat Jowo. Berziarah dan membersihkan kubur Kyai Modjo atau "pungguan" menjelang bulan Ramadhan seperti yang umum juga dilakukan oleh masyarakat Jawa.

Meskipun demikian, tradisi "pungguan" mulai bercampur dengan nilai baru datang dari masyarakat kristiani yaitu setelah bersih kubur mereka makan-makan di daerah pemakaman. Cara meneruskan nilai dan norma ini adalah dengan tetap teguh melaksanakan berbagai tradisi keislaman yang diperoleh dari generasi sebelumnya.

Norma yang berlaku pada masyarakat Jaton tampaknya juga mulai membaur dengan budaya masyarakat Minahasa. Tidak ada batasan atau aturan kaku yang membatasi sikap kerukunan antar kelompok. Kedua kelompok hidup rukun dan saling menghormati. Hal tersebut antara lain disebabkan oleh perkawinan campur yang tampaknya cukup lazim terjadi diantara kedua kelompok ini.

Masyarakat Jaton masih memegang nilai budaya leluhur yang berasal dari pulau Jawa akan tetapi tampaknya bila keluarga berbeda latar belakangnya maka berbeda pula nilai yang diturunkan. Seperti ada keluarga Jaton yang tidak memperbolehkan keturunannya untuk menikah dengan orang Kristen. Akan tetapi ada keluarga yang merasa bila anaknya menikah dengan orang Kristen tidak menjadi masalah.

\section{Daftar Pustaka}

Alwie, T. (2008). Kerukunan Muslim (Jawa) di Tanah Minahasa. Retrieved January 17, 2019, from http://arsip. gatra.com/2008-09-29/majalah/artikel. php?pil=23\&id=119302

Babcock, T. (1981). Muslim Minahasans with Roots in Java: The People of Kampung Jawa Tondano. Indonesia. https://doi. org/10.2307/3350856

Dasrun, H., Kuswarno, E., Zubair, F., \& Hafiar, H. (2017). Negosiasi Citra Budaya Masyarakat Multikultural. Jurnal ASPIKOM, 3(2), 157-172. Retrieved from http://jurnalaspikom.org/ index.php/aspikom/article/view/125/119

Haviland, W. A., Prins, H. EL, McBride, B., \& Walrath, D. (2010). Cultural Anthropology: The Human Challenge. Cengage Learning.

inrevolzon, I. (2013). Kebudayaan dan Peradaban. TAMADDUN: Jurnal Kebudayaan Dan Sastra Islam, 13(2). Retrieved from http://jurnal.radenfatah. ac.id/index.php/tamaddun/article/ view/152/137

Lay, C. (2009). Kekerasan Atas Nama Agama: Perspektif Politik. Jurnal Ilmu Sosial Dan Ilmu Politik, 13(1), 1-19. https:// doi.org/10.22146/JSP.10964

Lexy J. Moleong, D. M. A. (2017). Metodologi Penelitian Kualitatif (Edisi Revisi). In PT. Remaja Rosda Karya. https://doi. org/10.1016/j.carbpol.2013.02.055

Liliweri, A. (2009). Makna Budaya Dalam Komunikasi Antarbudaya. Yogyakarta: LkiS.

Martinus, A. (2016). Kampung Jawa Tondano. Dari Kyai Modjo hingga Penyebaran Islam di Minahasa - Halaman 2 - Tribun Manado. Retrieved January 17, 2019, from http:// manado.tribunnews.com/2016/11/20/ kampung-jawa-tondano-dari-kyai- 
modjo-hingga-penyebaran-islam-diminahasa?page $=2$

Nugroho, A. B., Lestari, P., \& Wiendijarti, I. (2012). Pola Komunikasi Antarbudaya Batak dan Jawa di Yogyakarta. Jurnal ASPIKOM, 1(5), 403-418. Retrieved from http://jurnalaspikom.org/index. php/aspikom/article/view/44/46

Prasetyo, A. (2011). Melacak Jejak Pengikut Diponegoro - Kompas.com. Retrieved January 17, 2019, from https://edukasi. kompas.com/read/2011/05/02/02491634/ melacak.jejak.pengikut.diponegoro

Rahmansyah, R. (2016). Keanekaragaman Budaya di Indonesia dan Semboyan Bhinneka Tunggal Ika - Kabar Rantau. Retrieved January 17, 2019, from https:// www.kabarrantau.com/keanekaragamanbudaya-indonesia-dan-semboyanbhinneka-tunggal-ika/

Samovar, L. A., Porter, R. E., \& McDaniel, E. R. (2010). Komunikasi Lintas Budaya (7th ed.). Salemba Humanika.

Suryani, W. (2013). Komunikasi Aantar Budaya yang Efektif. Jurnal Dakwah
Tabligh, 14(1), 91-100. Retrieved from http://journal.uin-alauddin.ac.id/index. php/tabligh/article/view/316/281

Suyanto, B., \& Sutinah, S. (2013). Metode Penelitian Sosial: Berbagai Pendekatan Alternatif(3rd ed.). Prenada Media Group.

Utama, M. R. J. (2017). Bentuk Komunikasi Dalam Akulturasi Budaya Suku Jawa dan Suku Bugis di Kelurahan Budaya Pampang Kecamatan Samarinda Utara Kota Samarinda. EJournal Ilmu Komunikasi, 5(3), 681-695. Retrieved from http://ejournal.ilkom.fisip-unmul. ac.id/site/wp-content/uploads/2017/10/ Jurnal Ja edit (10-11-17-03-35-59).pdf

Wolojan, F. (2015). Ziarah ke Makam Kyai Mojo di Minahasa, Sang Penasihat Spiritual Pangeran Diponegoro - Halaman all - Tribunnews.com. Retrieved January 17, 2019, from http://www.tribunnews. com/travel/2015/06/21/ziarah-kemakam-kyai-modjo-sang-penasihatspiritual-pangeran-diponegoro?page=all

Yin, R. K. (2014). Case Study Research Design and Methods (5th ed.). Thousand Oaks. 